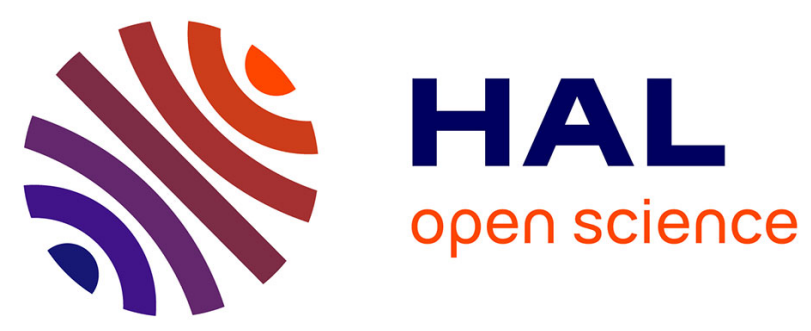

\title{
Impact of water and thermal induced crystallizations in a PC/MXD6 multilayer film on barrier properties
}

Tiphaine Messin, Stéphane Marais, Nadège Follain, Corinne Chappey, Alain

Guinault, Guillaume Miquelard-Garnier, Nicolas Delpouve, Valérie Gaucher, Cyrille Sollogoub

\section{To cite this version:}

Tiphaine Messin, Stéphane Marais, Nadège Follain, Corinne Chappey, Alain Guinault, et al.. Impact of water and thermal induced crystallizations in a PC/MXD6 multilayer film on barrier properties. European Polymer Journal, 2019, 111, pp.152-160. 10.1016/j.eurpolymj.2018.12.021 . hal-02063888

\section{HAL Id: hal-02063888 \\ https://hal.science/hal-02063888}

Submitted on 11 Mar 2019

HAL is a multi-disciplinary open access archive for the deposit and dissemination of scientific research documents, whether they are published or not. The documents may come from teaching and research institutions in France or abroad, or from public or private research centers.
L'archive ouverte pluridisciplinaire HAL, est destinée au dépôt et à la diffusion de documents scientifiques de niveau recherche, publiés ou non, émanant des établissements d'enseignement et de recherche français ou étrangers, des laboratoires publics ou privés. 


\title{
Impact of water and thermal induced crystallizations in a PC/MXD6 multilayer film on barrier properties
}

\author{
Tiphaine Messin ${ }^{\mathrm{a}}$, Stéphane Marais ${ }^{\mathrm{a}, *}$, Nadège Follain ${ }^{\mathrm{a}}$, Corinne Chappey ${ }^{\mathrm{a}}$, Alain Guinault ${ }^{\mathrm{b}}$, \\ Guillaume Miquelard-Garnier $^{\mathrm{b}}$, Nicolas Delpouve ${ }^{\mathrm{c}}$, Valérie Gaucher ${ }^{\mathrm{d}}$, Cyrille Sollogoub ${ }^{\mathrm{b}}$

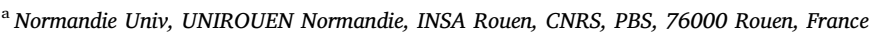 \\ ${ }^{\mathrm{b}}$ PIMM, Arts et Métiers ParisTech/CNRS/CNAM, 75013 Paris, France \\ ${ }^{\mathrm{c}}$ Normandie Univ, UNIROUEN Normandie, INSA Rouen, CNRS, GPM, 76000 Rouen, France \\ ${ }^{\mathrm{d}}$ Unité Matériaux et Transformations, UMR 8207 CNRS/Université Lille, 59655 Villeneuve d'Ascq, France
}

\section{A B S T R A C T}

A multilayer film composed of alternating layers of polycarbonate (PC) and poly(m-xylene adipamide) (MXD6) was elaborated by using an innovative multilayer coextrusion process. Quasi-continuous thin MXD6 layers (nanolayers) alternating with PC layers were successfully obtained. The PC/MXD6 multilayer film showed a confining effect of MXD6 exerted by PC layers leading to an improvement of barrier properties despite a low degree of crystallinity $\left(\mathrm{X}_{\mathrm{c}}<10 \mathrm{wt} \%\right)$. In order to further improve the barrier performances, crystallization treatments induced by water and by heating were then applied on the multilayer film and allowed reaching around $30 \mathrm{wt} \%$ of crystallinity in MXD6 layers. To decouple crystallization and geometrical constraint effects on the barrier properties in the multilayer films, the two treatments were also applied on MXD6 films. Surprisingly, despite an increase of the degree of crystallinity from 6 to $26 \%$, water crystallization did not permit to improve gas barrier performances of the MXD6 film nor into the PC/MXD6 multilayer film. On the other hand, thermal crystallization of MXD6 in the multilayer film seems to be a more efficient route to strongly decrease the gas and moisture permeability, up to $75 \%$ for nitrogen, $58 \%$ for oxygen, $84 \%$ for carbon dioxide and $43 \%$ for water.

\section{Introduction}

Polymer films or membranes are present in our daily environment and used in several industrial fields like energy, transport, aircraft, building, biomedical, protective coatings or packaging for example. For technological and economic reasons, both lightening polymeric materials and enhancing their thermo-mechanical and barrier properties, are increasingly desired industrial goals [1-3].

An innovative process, multilayer coextrusion, has been developed for producing thin multilayer films, which consist of hundreds to thousands alternating layers of two polymers. This technique is based on the use of layer multiplying elements (LME) placed at the output of a conventional coextrusion process. The layer multiplying elements vertically separate the flow of polymer melts in two parts and subsequently recombine them by stacking. While keeping constant the whole thickness, after each passage through layer multiplying elements the number of layers is multiplied by 2 , hence their individual thickness is divided by 2 . Thus, depending on the number of multiplying elements, the final structure can be composed of a very large number of alternating layers. With the multiplication of nanolayers, new polymer morphologies in the film can be induced by crystallization under confinement arising from the forced assembly phenomenon [4,5]. Such morphologies led to much improved barrier properties for many polymer pairs [6-8], compared to properties resulting from conventional polymer blends or micronic multilayer structures. Indeed, it has been shown that the best barrier properties are obtained when the crystallization of semi-crystalline polymers in a confined space leads to the formation of crystalline lamellae oriented in the in-plane direction [9-12], that is to say perpendicular to the diffusing molecule pathway, thus creating a very high barrier layer. The development of polymer films made of ultra-thin alternating layers is then a new challenge both from the technological point of view and from the implementation of characterization tools suited to these new materials.

In a previous paper on the elaboration of a polycarbonate (PC)/poly (m-xylene adipamide) (MXD6) multilayer film [13], an improvement of the MXD6 barrier performances was obtained due to a confinement effect induced by the PC under multilayer form. Even if the degree of crystallinity of MXD6 was close to only $8 \%$, the barrier properties of the MXD6 were improved by a factor of $60 \%$ in the case of nitrogen and oxygen and $13 \%$ in the case of water as permeant molecules. Knowing that the MXD6 can crystallize until 30\% [14], it became interesting to reach this maximum amount by increasing the crystalline phase fraction and to see at which point the barrier performances of the multilayer film can be enhanced by post-processing treatment. Therefore,

\footnotetext{
* Corresponding author.

E-mail address: stephane.marais@univ-rouen.fr (S. Marais).
} 
two types of crystallization treatments have been applied on the PC/ MXD6 multilayer film. The first crystallization treatment consists in heating the multilayer film at the crystallization temperature of the MXD6 and the second one in immersing the sample into liquid water as MXD6 is able to crystallize in contact with water [13]. It has already been demonstrated that the water sorption into MXD6 produced a glassto-rubber transition, which facilitated the crystallization of the polyamide thanks to the rearrangement of the polymer chains [15]. Nowadays, few works about the crystallization of MXD6 films by water or thermal treatments have been published and they lead to an improvement of the water and oxygen permeability $[14,16,17]$ Gas $\left(\mathrm{N}_{2}\right.$, $\mathrm{O}_{2}, \mathrm{CO}_{2}$ ) and water behaviors of these multilayer PC/MXD6 films were analyzed from flux permeation kinetics and the resulting barrier properties were correlated to the morphological and structural changes induced by these crystallized multilayer films. Because both the confinement effect induced in the multilayer and the crystallization may have concomitant effects on the barrier properties, the structure and transport properties of MXD6 film were also investigated.

\section{Experimental}

\subsection{Materials}

PC, referenced as LEXAN 121R $\left(\mathrm{Mw}=33,050 \mathrm{~g} / \mathrm{mol}, \mathrm{Tg}=145^{\circ} \mathrm{C}\right)$, was obtained from SABIC and MXD6, under the grade 6007 $\left(\mathrm{Mn}=25,900 \mathrm{~g} / \mathrm{mol}, \mathrm{Tg}=85^{\circ} \mathrm{C}, \mathrm{Tm}=237^{\circ} \mathrm{C}\right)$ was supplied by Mitsubishi Gas Chemical. The PC and MXD6 pellets were dried at $120^{\circ} \mathrm{C}$ overnight and the residual moisture before processing was found to be less than $0.02 \%$ for PC and $0.1 \%$ for MXD6. In the typical range of shear rates occurring in the extruders $\left(1-100 \mathrm{~s}^{-1}\right)$ at a processing temperature of $240{ }^{\circ} \mathrm{C}$, the viscosity ratio $\left(\eta_{\mathrm{MXD} 6} / \eta_{\mathrm{PC}}\right)$ between the two polymers was close to 2 .

\subsection{Films preparation}

The layer-multiplying coextrusion process is illustrated in Fig. 1. It consists in melting each polymer in an extruder and combining them as a 3-layers polymer flow into a classical A/B/A coextrusion feedblock. Then, the 3-layer flow goes through a series of layer multiplying elements (LME). By taking into account the number of multiplying elements noted $n$, the total number of layers can be determined with the following equation:

Number of layers $N=2^{(n+1)}+1$

The PC/MXD6 multilayer film, containing $80 \mathrm{wt} \%$ of PC and $20 \mathrm{wt} \%$ of MXD6, was prepared by melting each polymer in an extruder (profile

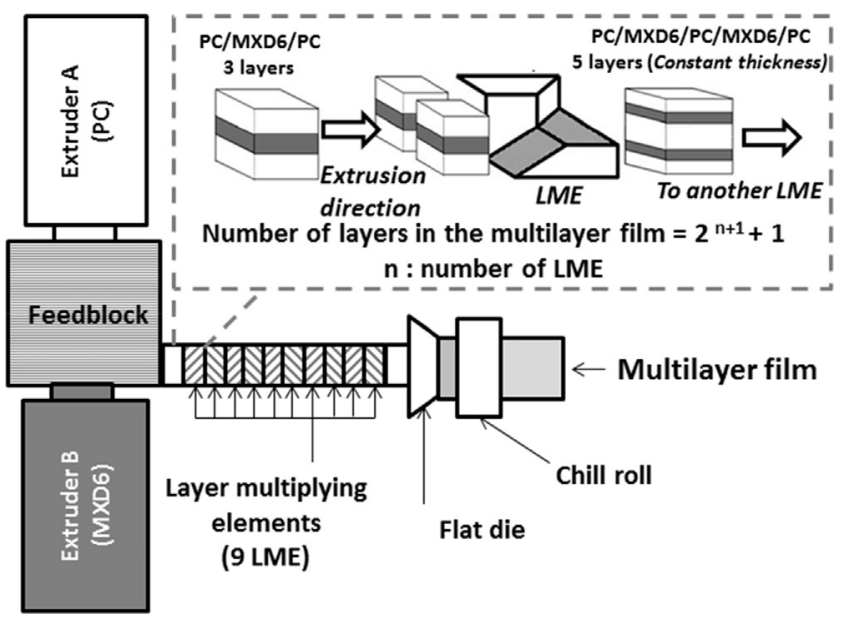

Fig. 1. Schematic principle of the layer-multiplying coextrusion process. temperature of the PC extruder from the hopper to the die: $310 / 280 /$ $260 / 260{ }^{\circ} \mathrm{C}$, screw speed of $31 \mathrm{rpm}$; profile temperature of the MXD6 extruder: $310 / 280 / 260 / 260^{\circ} \mathrm{C}$, a screw speed of $31 \mathrm{rpm}$ ), and then combined using 9 multiplying elements (giving rise theoretically to 1025 layers) at $240^{\circ} \mathrm{C}$. Then a flat die at $240{ }^{\circ} \mathrm{C}$ followed by a chill roll set at $130^{\circ} \mathrm{C}$ were used to obtain a final film having a total thickness of $200 \mu \mathrm{m}$.

The MXD6 monolayer film was obtained using a classical singlescrew extruder (Scamex extruder with a diameter $20 \mathrm{~mm}$ and a lengthto-diameter ratio of 20) with a screw speed of $40 \mathrm{rpm}$ and a temperature profile of $310 / 280 / 260 / 260{ }^{\circ} \mathrm{C}$. The chill-roll temperature was $90{ }^{\circ} \mathrm{C}$ and the final thickness of the film was $260 \mu \mathrm{m}$.

All the films were stored in a desiccator with $\mathrm{P}_{2} \mathrm{O}_{5}$ under vacuum to prevent moisture recovery before further characterizations.

\subsection{Crystallization treatments}

The crystallization of MXD6 induced by water in the PC/MXD6 film was performed by immersing the samples directly in liquid water (milli$\mathrm{Q}$ water) at $25^{\circ} \mathrm{C}$ for $48 \mathrm{~h}$. This duration time was determined from the water sorption kinetic curve which reaches an equilibrium state (plateau) after $24 \mathrm{~h}$, indicating no further absorption of water. The samples were left one more day in water to ensure a complete crystallization. The samples were thereafter dried under vacuum at $45^{\circ} \mathrm{C}$ for $24 \mathrm{~h}$ to remove all the water molecules still present in the films.

The thermally induced crystallization of MXD6 in the PC/MXD6 film was carried out by directly hot-pressing the samples (under hydraulic pressure, $\mathrm{P}=20 \mathrm{MPa}$ ) at $140{ }^{\circ} \mathrm{C}$ for $5 \mathrm{~min}$, i.e. until the disappearance of the cold crystallization peak (around $120^{\circ} \mathrm{C}$ ). The temperature of $140{ }^{\circ} \mathrm{C}$ during pressing was selected close to the cold crystallization temperature of MXD6 and below the glass transition temperature of PC in order to preserve as much as possible the multilayer structure. Films that have not been thermally treated will be noted as 'initial films' in the paper.

\subsection{Morphological characterization}

The morphology of the monolayer MXD6 films (thermally and water crystallized) was observed by using an Hitachi 4800 Scanning Electron Microscope. The observed section was obtained after a cryo-fracture and a fine deposit of gold was made to increase the conductivity of the polymer.

The multilayer structure was observed by using a transmission electron microscope Tecnai $\mathrm{G}^{2}$ (Philips) with an $80 \mathrm{kV}$ acceleration voltage. The samples were cut at ambient temperature using an ultramicrotome (LKB BROMMA 2088 Ultramicrotome) equipped with a diamond knife to obtain ultra-thin sections subsequently transferred to G200-Cu grids. A treatment with ruthenium tetroxide $\left(\mathrm{RuO}_{4}\right)$ vapour was applied on the samples during $10 \mathrm{~min}$ in order to improve the contrast between the PC and MXD6 layers.

\subsection{Structural characterizations}

Thermal properties of the films were analyzed from a DSC Q2000 from TA Instruments at a heating/cooling rate of $10^{\circ} \mathrm{C} / \mathrm{min}$ from -10 to $300{ }^{\circ} \mathrm{C}$. The degree of crystallinity, determined from the first heating step (which corresponds to the physical state in which the samples were during the permeation measurements), was calculated from the following equation:

$X_{c}(\%)=\frac{\Delta H_{m}-\Delta H_{c c}}{\Delta H_{m}^{0}} * 100$

where $\Delta H_{c c}$ is the enthalpy of crystallization, $\Delta H_{m}$ is the enthalpy of melting, and $\Delta H_{m}^{0}$ is the theoretical enthalpy of melting for a $100 \%$ crystalline polymer. In the case of MXD6, $\Delta H_{m}^{0}$ is equal to $175 \mathrm{~J} / \mathrm{g}$ [16].

WAXS patterns were obtained by using a SAXS/WAXS laboratory 
beamline composed of GeniX3D Cu ultra low divergence microsource operated at $50 \mathrm{kV}$ and $0.6 \mathrm{~mA}$. The $\mathrm{Cu}-\mathrm{K} \alpha$ radiation $(\lambda=1.54 \AA)$ was collimated with a FOX2D mirror and two pairs of Scatterless slits from Xenocs. Through- and edge-views 2-D WAXS patterns were recorded on a Pilatus $200 \mathrm{~K}$ detector. Radial intensity profiles $I(2 \theta)$ were obtained by using FIT2D software which allows to an azimuthal integration of the 2D-patterns. To characterize the crystalline phase, the average WAXS diffractogram is calculated from normalized radial intensity profiles I (20) recorded in the three principal directions of film. Crystal index was determined using the PeakFit software, and assuming Pearson profiles for all scattering peaks and amorphous halo. The assignments of the crystalline peaks were based on previous works of Ohta et al. [18]. Small Angle X-ray scattering (SAXS) experiments were performed to reveal the presence of a long period $\mathrm{L}_{\mathrm{p}}$ corresponding to the periodic stacking of alternating amorphous and crystalline regions thanks to the electron density contrast between these two phases.

\subsection{Transport properties}

\subsubsection{Gas permeation}

Gas permeation measurements were carried out at $25^{\circ} \mathrm{C}$ by using the typical "time-lag technique" based on the barometric method $[19,20]$ and the measurements were made at least 2 times. A film was placed between the two compartments (the upside and the downside compartments) of the permeation cell. Before starting the measurement to obtain the gas permeation kinetics, a preliminary purge step was performed by applying a vacuum to the system for $15 \mathrm{~h}$. Then, after feeding the upside compartment with the selected gas $\left(\mathrm{N}_{2}, \mathrm{O}_{2}\right.$, or $\left.\mathrm{CO}_{2}\right)$ at a pressure of 4 bars, the increase of pressure in the downside compartment of the permeation cell, caused by the diffusion of gas molecules through the film, was monitored by a pressure sensor. The slope $\alpha$ of the kinetic curve (increase of pressure as a function of time) at long time allowed the determination of the stationary flux, noted $J_{s t}$, from the following equation:

$J_{s t}=\frac{\alpha * V}{A * R * T}$

with $V$ is the volume of the downside compartment, $R$ is the ideal gas constant, $A$ is the surface of film exposed to gas and $T$ is the experimental temperature.

Knowing the value of the stationary flux $J_{s t}$, the permeability coefficient $P$ can be determined according to:

$P=\frac{J s t * L}{\Delta p}$

where $L$ is the film thickness and $\Delta p$ is the difference of pressure between the upstream and the downstream compartments. Usually, for gas barrier properties, the permeability unit is in Barrer (1 Barrer $=10^{-10} \mathrm{~cm}^{3}(\mathrm{STP}) \cdot \mathrm{cm} \cdot \mathrm{cm}^{-2} \cdot \mathrm{s}^{-1} \cdot \mathrm{cmHg}^{-1}$ ). STP for Standard conditions of Temperature and Pressure.

\subsubsection{Water permeation}

Water permeation measurements were achieved at $25^{\circ} \mathrm{C}$ with a home-made apparatus, which is composed of a permeation cell containing an upstream and a downstream compartments separated by the tested film. The quantity of transferred water molecules within the film accumulating in the downside compartment was monitored by a chilled mirror hygrometer (Elcowa ${ }^{\circledR}$, France, General Eastern Instruments) giving the dew point temperature of the sweeping gas. To eliminate the moisture in the cell, the two compartments were initially swept with dry nitrogen until reaching a low dew point temperature around $-70{ }^{\circ} \mathrm{C}(\sim 2.5 \mathrm{ppmV})$. Then, while the downside compartment was continuously swept by nitrogen flux, the upside compartment was filled with liquid water (milli-Q water). Due to the water gradient concentration (driving force) between both sides of the film, water molecules diffuse through the film and their quantity was measured by following the variation of the dew-point temperature as a function of time. The water permeation flux $J$ occurring through the film is then determined from the following equation [21]:

$J=\frac{f \cdot 10^{-6}\left(X_{w}^{\text {out }}-X_{w}^{\text {in }}\right)}{S \cdot R \cdot T} \cdot p_{t}$

where $f$ is the flow rate of the sweeping gas $\left(9.3 \mathrm{~cm}^{3} \mathrm{~s}^{-1}\right), X_{w}^{\text {out }}-X_{w}^{\text {in }}$ is the water concentration calculated from the dew point temperature $\mathrm{T}_{\mathrm{dp}}$ of the sweeping gas $\left(X_{w}=\exp \left(-6185.6 / T_{d p}+31.4\right)\right), \mathrm{S}$ is the film surface area $\left(2.5 \mathrm{~cm}^{2}\right), \mathrm{R}$ is the ideal gas constant, $\mathrm{T}$ is the temperature of the experiment $(298 \mathrm{~K})$ and $\mathrm{p}_{\mathrm{t}}$ is the total pressure in the cell $(1 \mathrm{~atm})$.

At the stationary state, the permeability coefficient $P$ was calculated according to:

$P=\frac{J_{s t} * L}{\Delta a}$

with $J s t$ is the stationary flux, $L$ is the thickness of the film and $\Delta a$ is the difference of water activity between the two compartments of the permeation cell (in our case $\Delta a=1$ ).

In addition to the water permeability coefficient, the water diffusivity $D$ was also determined from the transient regime of the permeation kinetic. In the particular case of MXD6 able to plasticize and to crystallize during the water permeation process, and on the basis of the water-concentration dependent diffusion coefficient [13], the diffusion coefficient was calculated at the beginning of transient period, at $24 \%$ of the maximum of the flux, i.e. with an effect of water concentration that can be neglected [16]:

$D=\frac{L^{2} \times 0.091}{t_{0.24}}$

This coefficient also corresponds to the inflection point of the theoretical curve for D constant, on the basis of Fick's law [22].

To compare the permeability results and to show the gain in barrier properties, a Barrier Improvement Factor (named BIF) was calculated as the difference between the permeability of a polymer in monolayer and multilayer form, divided by the permeability of the polymer under monolayer form:

BIF $(\%)=\frac{P_{M X D 6} \text { monolayer }-P_{M X D 6} \text { into } P C / M X D 6 \text { film }}{P_{M X D 6} \text { monolayer }}$

\section{Results and discussion}

\subsection{Impact of crystallization treatments on MXD6 monolayer film}

\subsubsection{Morphology}

SEM experiments were carried out on the thermally and the water crystallized MXD6 films in order to verify if the structure of the film has been changed during the crystallization. As observed in Fig. 2, the cross section of the MXD6 water crystallized (Fig. 2.a) is not regular compared to the MXD6 film thermally crystallized (Fig. 2.b) which presents a flat and smooth surface. SEM images reveal that the water crystallized film has some empty spaces, similar to pinholes, which are located in the core of the film while the MXD6 thermally crystallized film does not present such microvoids. It is very likely that the presence of these microvoids will affect the diffusion of penetrant species at point to modify the barrier properties of the films. This point will be discussed later.

\subsubsection{Structure characterization}

DSC measurements were performed first on the MXD6 films, before and after they have undergone the crystallization treatments. The samples characteristic temperatures (the glass transition temperature $T_{g}$, the crystallization temperature $T_{c c}$ and the melting temperature $T_{m}$ ) and the degree of crystallinity are gathered in Table 1 , while the corresponding curves can be found in Supporting Information. By 


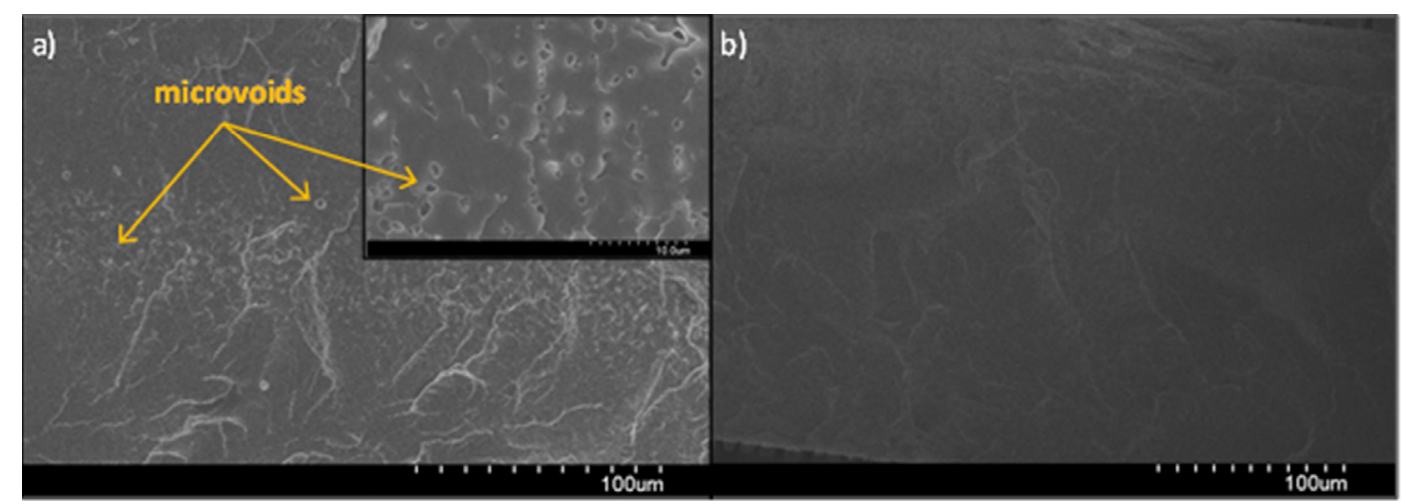

Fig. 2. SEM images of the cross section of the (a) water crystallized and (b) thermally crystallized MXD6 films.

comparing the two crystallized MXD6 films with the reference MXD6 film, no significant variation of the characteristic temperatures can be observed, excepted for the cold crystallization which disappears in the case of the crystallized films. This result can be correlated to the fact that all the crystals were formed during the thermal or the water crystallization. Indeed, an increase in the degree of crystallinity from $6 \%$ to about $30 \%$ was obtained after the two crystallization treatments, the highest degree of crystallinity being obtained in the case of the thermal treatment. From these structural changes, it can be expected that the barrier properties of the annealed MXD6 films should be better than those of the initial MXD6 film.

$\mathrm{XRD}$ analyses were performed on the thermally and water crystallized MXD6 films to check if there is a difference of microstructure between the two types of crystallized MXD6. The comparison of the two diffractograms (Fig. 3a) reveals a similar crystalline structure with a crystal index of about $40 \%$. The deconvolution of WAXS diffractograms for the two films (Fig. 3b and c) suggests a slightly smaller size of coherence domains for water crystallized MXD6 film. SAXS experiments reveal a long period of about $8 \pm 1 \mathrm{~nm}$ for both thermally and water crystallized MXD6 films, showing that lamellae are regularly stacked whatever the crystallization treatment. To sum up, the X-ray analysis seems to reveal similar crystalline structure whatever the treatment at a nanometer scale.

\subsubsection{Barrier properties to gas and to water}

Gas permeability coefficients of the MXD6 films were calculated from the stationary permeation fluxes and the obtained values for the three films are displayed in Fig. 4. First, the obtained gas permeability coefficients are found higher than those given in the literature (permeability to oxygen at $0 \% \mathrm{HR}$ close to $0.003-0.004$ Barrer [23,24] and 0.008 Barrer [25]) and than those already measured to $\mathrm{CO}_{2}$ from another MXD6 film (0.001 Barrer) in a previous study [17]. However, according to the literature, it must be considered that the gas permeability of MXD6 is strongly dependent not only on the structure (crystallinity, orientation, molecular weight) but also on the hydration state as it can easily plasticize with low water concentration [13]. Concerning the reference (black) and the thermally crystallized (orange) MXD6 films, the value of the permeability coefficient was similar for the three gases (0.03 and 0.02 Barrer respectively). Better barrier properties were obtained for the thermally-crystallized MXD6 film compared to the reference film: the barrier effect was increased by $35 \%$ for nitrogen, $38 \%$ for oxygen and $41 \%$ for carbon dioxide. This result is consistent with the increase of the degree of crystallinity (from $6 \%$ to $33 \%$ ) considering crystals as impermeable obstacles to diffusing species. Surprisingly, the water-crystallized MXD6 film possesses lesser barrier properties than the reference film while the degree of crystallinity is higher (26 vs. $6 \%$ ) and close to that of the thermally-crystallized film. This phenomenon could be associated with the drying step, performed after the water-crystallization treatment (done to remove all the water molecules trapped inside the film because of the strong interactions between amide groups), which has created some microvoids in the structure, as shown previously on Fig. 2, helping the diffusion of molecules through the film. Note that the water crystallized film is whiter than the thermally-crystallized one. This observation is in good agreement with the presence of larger cavities in this film. Indeed, as reported in literature, microvoids may cause light scattering leading to whitening of materials [26]. Despite the lack of barrier effect to $\mathrm{O}_{2}$ and $\mathrm{CO}_{2}$, it would however explain the slight barrier effect to $\mathrm{N}_{2}$ which has the higher dynamic diameter $(3.64 \AA)$ compared to $\mathrm{O}_{2}(3.46 \AA)$ and to $\mathrm{CO}_{2}(3.30 \AA)$ [27]. Moreover, contrary to the tendency usually observed in the literature [28] about the gas permeability ranking, $\mathrm{P}_{\mathrm{CO} 2}>\mathrm{P}_{\mathrm{O} 2}$, the water-crystallized MXD6 film displayed $\mathrm{P}_{\mathrm{CO} 2}<\mathrm{P}_{\mathrm{O} 2}$. There is no clear explanation to explain such permeability ranking between $\mathrm{CO}_{2}$ and $\mathrm{O}_{2}$. On the one hand it seems that the permeability of water-crystallized film to oxygen is relatively high and on the other hand we can hypothesize that there is a condensation phenomenon of some carbon dioxide molecules in the microvoids as they can be trapped due to wellknown affinity for amine groups present in MXD6, and consequently to a slower diffusion pathway, generating a lower permeability coefficient.

Water permeation kinetic measurements were performed on the MXD6 samples and the water permeation flux curves are plotted in Fig. 5 using a reduced scale (J.L versus $t / L^{2}$ ) to get rid of the film thickness influence. As previously reported $[13,17]$, an atypical reduced water permeation curve was observed for the reference MXD6 film. During the first permeation measurement (noted first passage of water, see Fig. 5) applied to the film, the flux curve was characterized by a maximum followed by a decrease as a function of time until reaching the stationary flux which corresponds to the steady state of permeation. This decrease is due to the crystallization induced by permeant water molecules, as confirmed by the increase from $6 \%$ to $30 \%$ in the degree of crystallinity (Table 2), which was measured at the

Table 1

Thermal properties of the MXD6 monolayer films before and after crystallization treatments.

\begin{tabular}{|c|c|c|c|c|}
\hline & $\operatorname{Tg}_{\text {MXD6 }}\left({ }^{\circ} \mathrm{C}\right)$ & $\operatorname{Tcc}_{\text {MXD6 }}$ (heat) $\left({ }^{\circ} \mathrm{C}\right)$ & $\operatorname{Tm}_{\text {MXD6 }}\left({ }^{\circ} \mathrm{C}\right)$ & $\mathrm{Xc}_{\mathrm{MXD} 6}(\%)$ \\
\hline MXD6 film & $50 \pm 2$ & $121 \pm 2$ & $236 \pm 2$ & $6 \pm 4$ \\
\hline MXD6 film Water-crystallized & $52 \pm 2$ & - & $235 \pm 2$ & $26 \pm 4$ \\
\hline MXD6 film Thermally-crystallized & $52 \pm 2$ & - & $236 \pm 2$ & $33 \pm 4$ \\
\hline
\end{tabular}



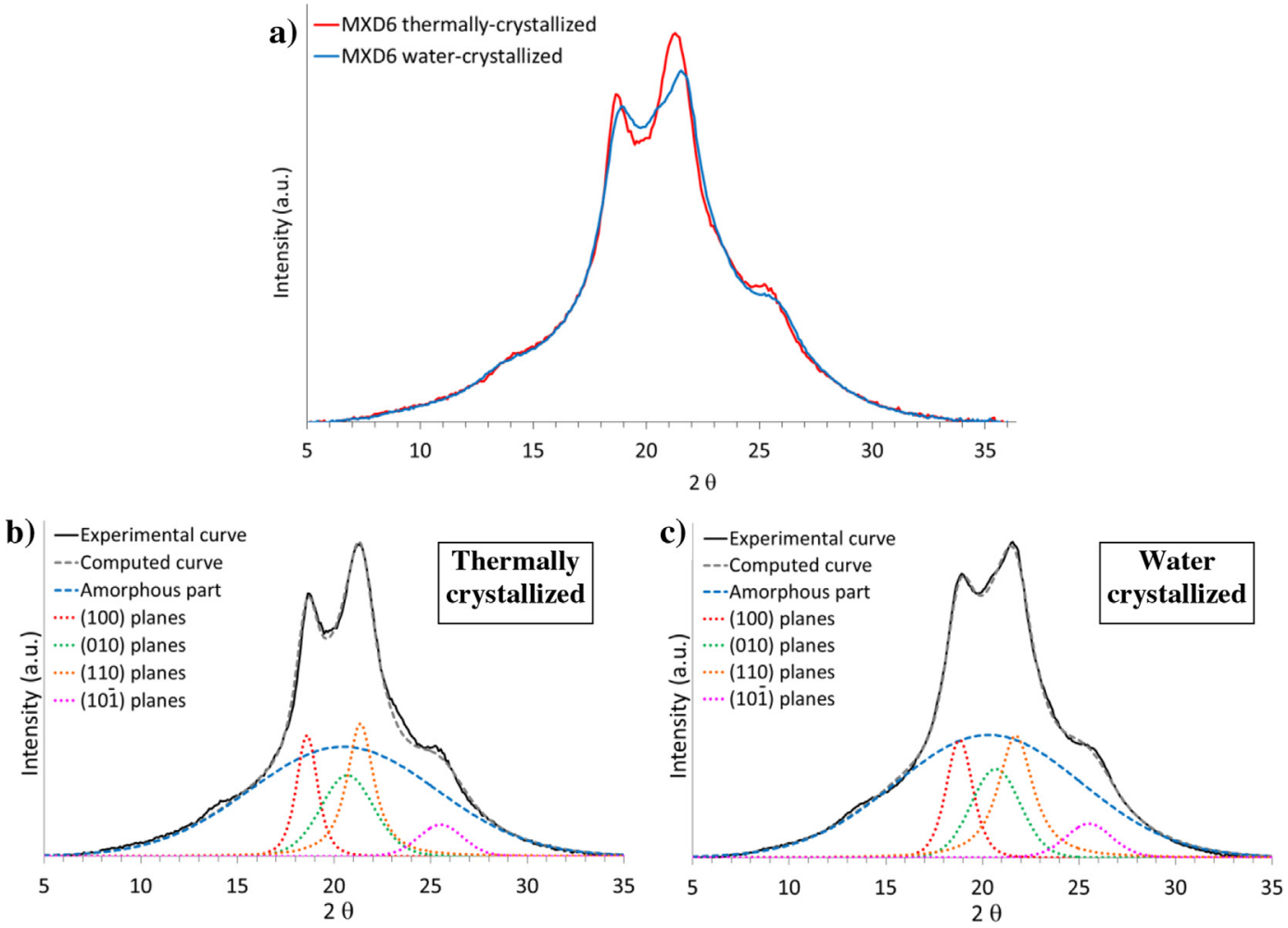

Fig. 3. WAXS diffractograms for the MXD6 film thermally and water-crystallized. (a) Comparison of the two crystallized MXD6 films, (b) deconvolution of WAXS diffractograms for MXD6 thermally-crystallized and (c) for the MXD6 water-crystallized.

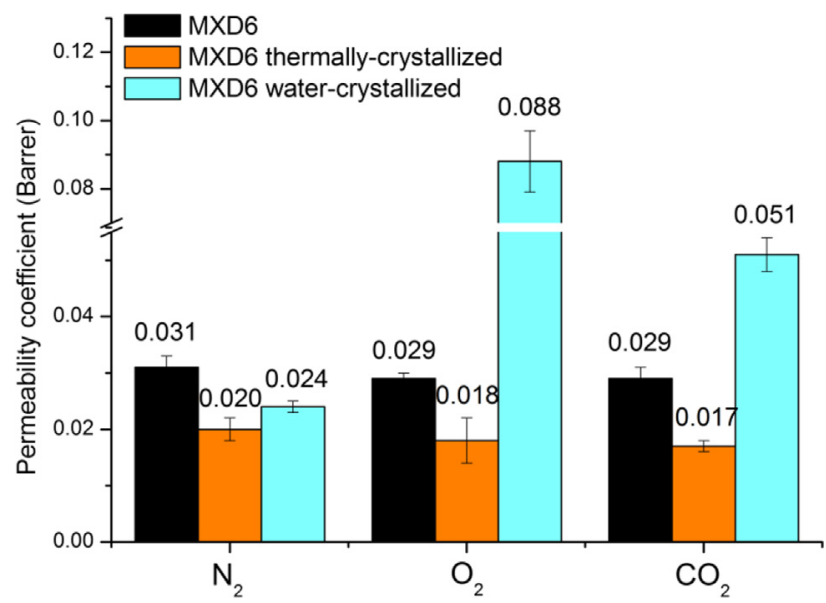

Fig. 4. Impact of the crystallization treatments on gas permeability coefficients for the MXD6 film.

end of the first passage of water. It has already been shown that this solvent-induced crystallization was possible because of the plasticization effect inherent of water in MXD6, which leads to an increase of the free volume and so in the chain segment mobility $[13,16]$. Then, a second permeation measurement (noted second passage of water, see Fig. 5) was applied to the same film but in which the water-induced crystallization has already occurred (during the first passage). As shown in Fig. 5, the two curves of the MXD6 film did not exhibit similar profile; the second curve exhibiting the typical permeation curve without dependence of time. Because of the crystallization phenomenon induced by water, the barrier properties of the film became better (lower stationary flux).

So, it became interesting to compare this behavior of the reference MXD6 film with that of the water-crystallized MXD6 film (immersion in water during $48 \mathrm{~h}$ ). As shown in Fig. 5 and Table 2, the value of the

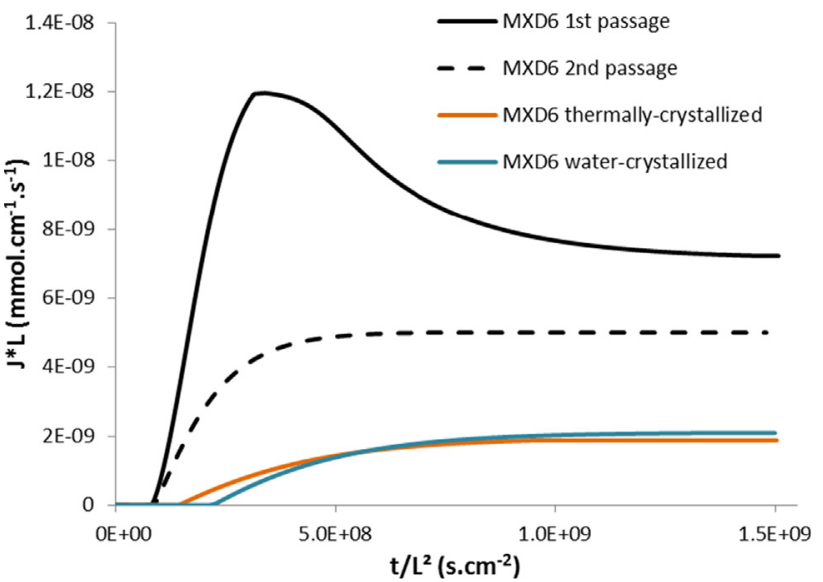

Fig. 5. Reduced water permeation curves for the MXD6 film before and after crystallization treatments.

Table 2

Liquid water permeation parameters for the MXD6 monolayer films.

\begin{tabular}{llll}
\hline & $\mathrm{X}_{\mathrm{c} \mathrm{MXD6}}(\%)$ & $\mathrm{P}($ Barrer $)$ & $\mathrm{D}\left(10^{-10} \mathrm{~cm}^{2} \cdot \mathrm{s}^{-1}\right)$ \\
\hline MXD6 film - 1st passage & 6 & $640 \pm 50$ & $9.8 \pm 3.0$ \\
MXD6 film - 2nd passage & 30 & $489 \pm 20$ & $5.6 \pm 1.0$ \\
MXD6 water-crystallized & 26 & $183 \pm 20$ & $2.9 \pm 0.1$ \\
BIF (\%) & - & 71 & - \\
MXD6 thermally-crystallized & 33 & $165 \pm 17$ & $3.5 \pm 0.8$ \\
BIF (\%) & - & 74 & - \\
\hline
\end{tabular}

* Calculated from the MXD6 film with a crystallinity degree of $6 \%$.

permeability coefficient (183 Barrer) was lower to that of the reference MXD6 film obtained after the two passages of water (489 Barrer). Moreover, we can note a reduction of the diffusion coefficient by a 
factor of two for the water-crystallized MXD6 film. This decrease of diffusivity can be explained by a difference in the penetration of the water molecules in the films. Indeed, during the permeation measurements, the water was in contact with a single face of the film contrary to the water-crystallization by immersion in water of the sample where the two faces of the film were in contact with the water molecules. In the first case, with the reference MXD6 film crystallized during the first passage of water, a front of formed crystals is moving along the film thickness, creating a gradient of structure through the material, as already observed by Buquet et al. [17] in a previous study. Thus, due to this non-symmetrical crystallization along the total film thickness, the structure was not homogenous, much more crystallized at the upside face of the film. The passage of water was slowed down at the beginning of the film and then less and less as the permeant water molecules pass through the film [17]. In the case of the water-crystallized MXD6 film (symmetrical crystallization), the structure was more homogeneous, reducing accordingly the mobility of the water molecules over the entire thickness of the film and thus allowing a larger improvement of the barrier properties (lower permeability).

By comparing the two crystallization treatments, it can be observed that both MXD6 films have practically the same water behavior but the barrier effect is slightly improved for the thermally-crystallized film. The amount of crystalline phase slightly higher for this film could explain this result. At this stage of the discussion, it is relatively surprising to note a water barrier effect improvement brought by the increased crystallinity with the water-crystallization treatment while for gas permeation, in particular for $\mathrm{O}_{2}$ and $\mathrm{CO}_{2}$, no barrier improvement was obtained. In the case of water, the situation is more complex as water molecules can interact with not only the polar components of MXD6 but also with themselves, leading to water clusters. The steric effect induced by water is thus different and higher than for gas molecules and, as a consequence, crystallinity plays here a key role. From that, the presence of cavities in the water crystallized MXD6 film is in agreement with the higher water permeability compared to that of the thermallycrystallized film (Table 2).

Finally, from water permeation results, we have shown that by applying a crystallization treatment, induced by heating or by water, the barrier properties of the MXD6 film were strongly improved around $70 \%$. Moreover, symmetric crystallization gives rise to a more homogenous crystallization in the film thickness, and consequently to a larger barrier effect.

In a previous study on a PC/MXD6 multilayer film [13], we have shown that the barrier properties of the MXD6 layers constrained by PC layers were improved while the degree of crystallinity of MXD6 was only $8 \%$.

In this work, because the barrier properties of MXD6 are dependent on the crystallization treatment used (thermally or water inducedcrystallization), it became interesting to see if the multilayer coextrusion process could further improve the barrier performances of the crystallized MXD6 layers (constrained by PC) and what would be the effect of the multilayer assembly on the crystallization treatment of MXD6 and the resulting transport properties.

\subsection{Impact of crystallization treatments on PC/MXD6 multilayer film}

\subsubsection{Morphology}

To determine the influence of the two crystallization treatments on the morphology of the PC/MXD6 (80/20 wt\%) multilayer films, transmission electronic microscopy (TEM) was performed and the resulting images are displayed in Fig. 6. The multilayer structure is clearly observed, with PC layers appearing in dark and MXD6 layers in grey, showing some areas with continuous layers (thickness around $300-700 \mathrm{~nm}$ ) but also some areas with defects (broken and/or coalesced layers). In fact, for the three films (initial, thermally and water crystallized), some parts of the films exhibit continuous and homogeneous structure while other part present some discontinuities or some breakups in the MXD6 layers. The pre-treated films having already irregularities, it seems that the treatments have not impacted significantly the multilayer structure. As the layers' thicknesses are on the order of several hundred nanometers, i.e. smaller than the typical size of the MXD6 spherulites, geometrical restriction (inducing preferential orientations for example) may occur, but significant effects due to confinement cannot be expected as they are usually observed for thicknesses below $\sim 100 \mathrm{~nm}[4,29,30]$.

\subsubsection{Structure characterization}

DSC analyses were carried out on the non-crystallized and crystallized PC/MXD6 multilayer films in order to confirm an increase in crystallinity of MXD6. No change in the PC glass transition and in the MXD6 melting temperature was observed, as revealed by the values gathered in Table 3. However, as above-mentioned in the case of the MXD6 films, the disappearance of the MXD6 cold crystallization was noted, which is explained by the fact that all the crystals were formed during the two crystallization treatments. The degree of crystallinity of MXD6, noted $\mathrm{X}_{\mathrm{C}}$ (calculated from the weight fraction of MXD6 in the film), was increased from $8 \%$ to more than $30 \%$ for both crystallization treatments. The amount of amorphous phase was accordingly decreased and it became very difficult to distinguish the glass transition of the MXD6, which was present at only $20 \mathrm{wt} \%$ in the PC/MXD6 multilayer film. Again, the higher degree of crystallinity of MXD6 was obtained for the thermally-crystallized treatment, as previously obtained for the MXD6 monolayer film.

\subsubsection{Barrier properties to gas and to water}

In terms of barrier properties, to evaluate the impact of the multilayer structure and of the crystallization treatments on the MXD6 when it was constrained by the PC under the multilayer form, the transport properties of the PC/MXD6 multilayer film were determined and analyzed by taken into account the water and gas permeability coefficients of the monolayer films of MXD6 and of PC. In a previous study [13], gas and water permeability coefficients of PC were measured ( 0.32 barrer for $\mathrm{N}_{2}, 1.5$ barrer for $\mathrm{O}_{2}, 7$ barrer for $\mathrm{CO}_{2}$ and 1730 barrer for $\mathrm{H}_{2} \mathrm{O}$ ). The low values so obtained indicate good barrier properties of the PC but which remain lower than ones of MXD6.

Considering that the amorphous structure of polycarbonate was not modified by the water sorption and nor by the thermal treatment which was performed at temperature under its glass transition temperature $\left(\mathrm{T}_{\mathrm{g}}=145^{\circ} \mathrm{C}\right)$, it is assumed that both crystallization treatments have effects only on the MXD6 into the multilayer film.

The influence of the crystallization treatments on the barrier properties of the PC/MXD6 multilayer film was analyzed from gas and water permeation kinetic measurements. First, gas permeation measurements were performed on the initial and the two crystallized PC/MXD6 multilayer films. The obtained permeability coefficients are compared in Fig. 7. As above-mentioned for the MXD6 monolayer film, the thermal crystallization treatment led to decrease the gas permeability coefficient. Indeed, as shown in Table 4, the thermal crystallization of the MXD6 polymer within the PC/MXD6 multilayer film allows the MXD6 barrier effect to be improved. However, like for the MXD6 monolayer film, the water crystallization treatment has contributed to decrease barrier properties of the PC/MXD6 multilayer film. A similar explanation can be proposed, that is to say an increase of the free volume due to the microvoid formation when removing the residual water molecules during the drying step by heating of the film. Again, this argument is supported by the more pronounced whitening of the water crystallized PC/MXD6 films.

In order to quantify the improvement of the barrier performances of the MXD6 layers within the PC/MXD6 multilayer film, assuming no geometrical constraint effect on amorphous PC, the permeability coefficient of the MXD6 layers was calculated by applying the series model equation $[5,6,10,31,32]$, and taking into account the experimental permeability coefficients of the multilayer film and of the PC monolayer 


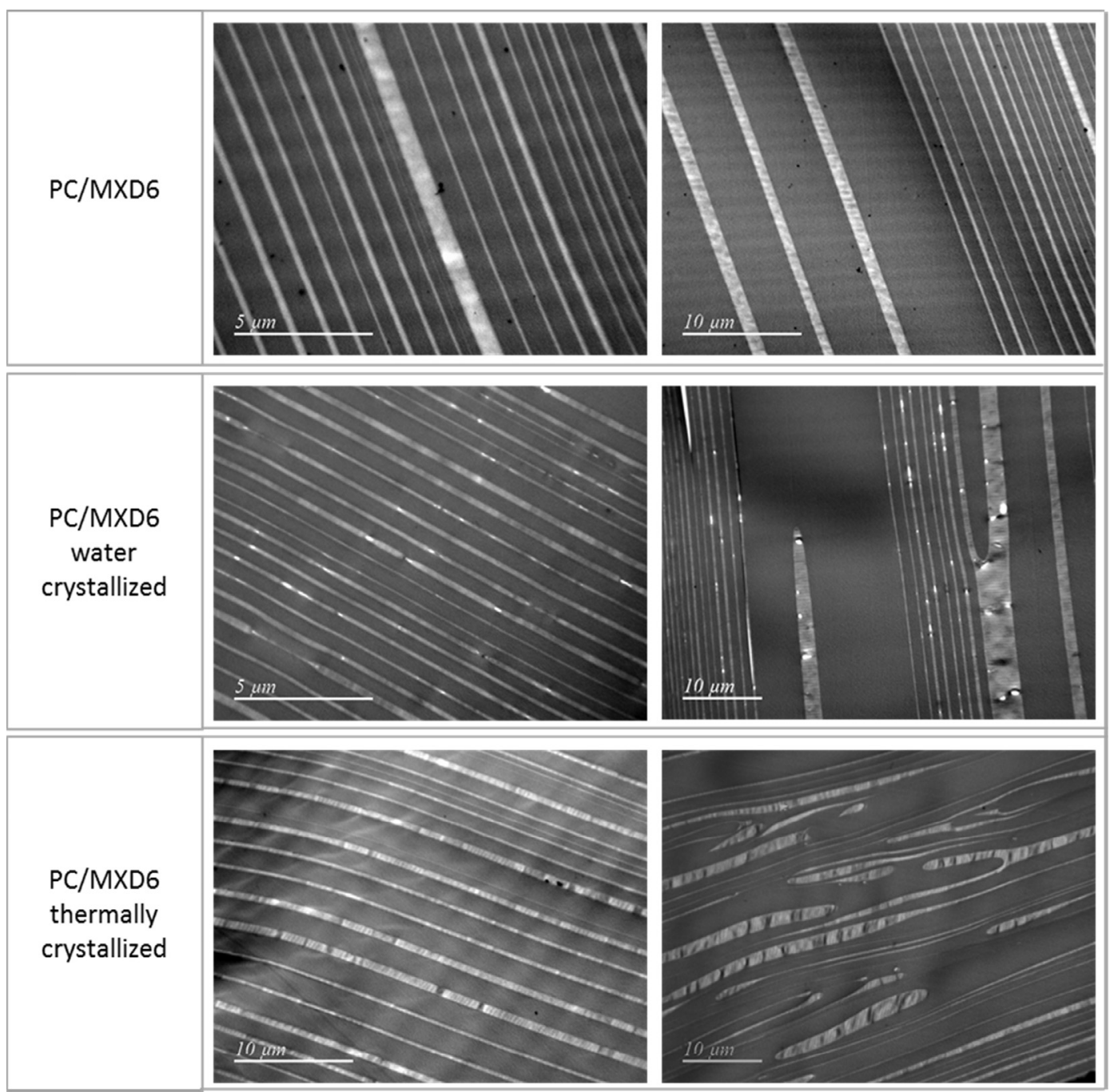

Fig. 6. TEM images for the initial and the crystallized PC/MXD6 multilayer films (PC: dark grey; MXD6: light grey).

Table 3

Thermal properties of the initial and the crystallized PC/MXD6 multilayer films.

\begin{tabular}{|c|c|c|c|c|c|}
\hline & $\operatorname{Tg}_{\text {MXD6 }}\left({ }^{\circ} \mathrm{C}\right)$ & $\operatorname{Tg}_{\mathrm{PC}}\left({ }^{\circ} \mathrm{C}\right)$ & $\mathrm{Tc}_{\mathrm{MXD} 6}$ (heat) $\left({ }^{\circ} \mathrm{C}\right)$ & $\operatorname{Tm}_{\mathrm{MXD}}\left({ }^{\circ} \mathrm{C}\right)$ & $\mathrm{Xc}{ }_{\text {MXD6 }}(\%)$ \\
\hline PC/MXD6 film water-crystallized & - & 142 & - & 233 & 31 \\
\hline PC/MXD6 film thermally-crystallized & - & 140 & - & 233 & 35 \\
\hline
\end{tabular}

film. The equation is as follows:

PMXD6 $=\frac{\varphi \mathrm{MXD6}}{\frac{1}{P \text { Film }}-\frac{\varphi \mathrm{PC}}{P \mathrm{PC}}}$

with $\varphi_{\mathrm{PC}}$ and $\varphi_{\mathrm{MXD6}}$ the volume fraction of PC (0.803) and MXD6 (0.197) within the multilayer film, respectively.

Doing so, the calculated permeability coefficients for the MXD6 are gathered in Table 4 and compared to the value of a reference film, which allows the barrier improvement factor, noted BIF, to be calculated. Thus, for the thermally-crystallized PC/MXD6 multilayer film, due to the presence of crystals within the MXD6 layers, a high gas barrier effect improvement for MXD6 was obtained (see value of BIF-1). Then, from a structural point of view, it is interesting to put forward the influence of the multilayer structure and then to see how the crystalline phase generated in the confined layers may change the barrier properties of the resulting film. First, from BIF-2, the inferred permeability of MXD6 in the as-extruded multilayers is lower than the one of the plain MXD6 film except for $\mathrm{CO}_{2}$. Such an improvement without an increase in crystallinity has already been observed in some multilayer films $[4,12,33]$. Also, from BIF-3, the inferred permeability of crystallized MXD6 in the multilayer is lower than in the plain crystallized film, although the crystallinity degree is similar. Again, the multilayer structure leads to increase the barrier effect of MXD6 constrained layers. In the case of crystallized MXD6, the improvement is at point that the barrier effect to $\mathrm{CO}_{2}$ is now obtained while it was not the case for the non-crystallized MXD6 layers within the multilayer film. Even if such effects are usually observed for lower thicknesses, it can be possible that the amorphous phase of MXD6 is much more constrained in thin layers, and the increased densification of this phase would reduce the molecular mobility of chains at the vicinity of the crystalline phase. Another explanation would be the presence of stronger hydrogen bonds in the structure favors by the multilayer structure. To see the possible orientation of crystals in the constrained MXD6 layers, XRD analyses were carried out on the face and on the cross section of the crystallized 


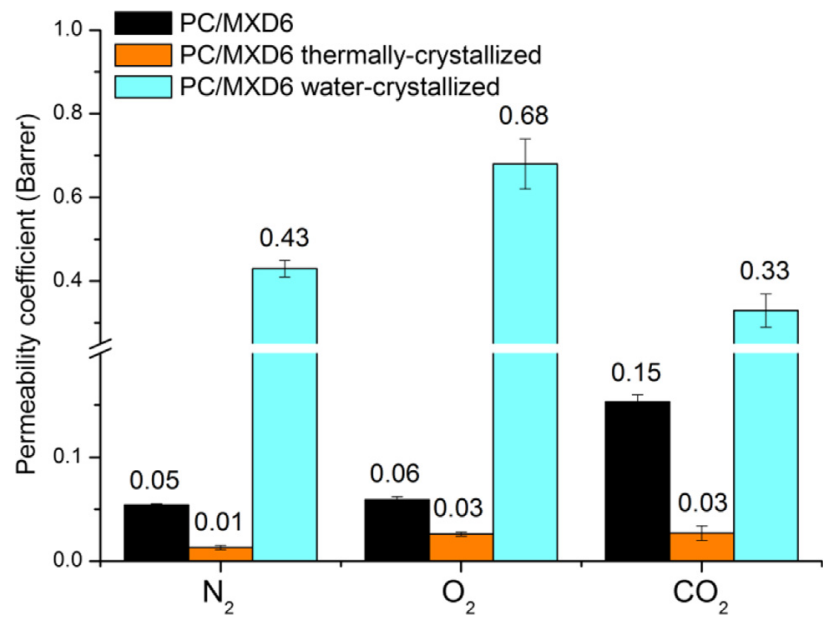

Fig. 7. Impact of the crystallization treatments on gas permeability coefficients for the PC/MXD6 multilayer films.

Table 4

Gas permeability coefficients of the MXD6 monolayer film and the PC/MXD6 multilayer films and the corresponding BIF factor of the MXD6. ("predicted values from series model).

\begin{tabular}{|c|c|c|c|c|}
\hline & & $\mathrm{N}_{2}$ & $\mathrm{O}_{2}$ & $\mathrm{CO}_{2}$ \\
\hline \multirow{6}{*}{$\begin{array}{l}\text { Permeability (in } \\
\text { barrer) }\end{array}$} & MXD6 monolayer film & & & \\
\hline & - non-crystallized & 0.031 & 0.029 & 0.029 \\
\hline & - thermally crystallized & 0.020 & 0.018 & 0.017 \\
\hline & PC/MXD6 multilayer film & & & \\
\hline & - MXD6 before crystallization & 0.012 & 0.012 & 0.031 \\
\hline & - MXD6 thermally crystallized & 0.003 & 0.005 & 0.005 \\
\hline BIF-1 & $\begin{array}{l}\text { MXD6 into the PC/MXD6 film after } \\
\text { thermal crystallization }\end{array}$ & $75 \%$ & $58 \%$ & $84 \%$ \\
\hline BIF-2 & $\begin{array}{l}\text { MXD6 into the non-crystallized PC/ } \\
\text { MXD6 film (compared to the non- } \\
\text { crystallized MXD6 monolayer film) }\end{array}$ & $61 \%$ & $59 \%$ & - \\
\hline BIF-3 & $\begin{array}{l}\text { MXD6 into the thermally crystallized } \\
\text { PC/MXD6 film (compared to the } \\
\text { thermally crystallized MXD6 } \\
\text { monolayer film) }\end{array}$ & $85 \%$ & $72 \%$ & $71 \%$ \\
\hline
\end{tabular}

FC/MXD6 film
water-crystallized
PC/MXD6 film
thermally-crystallized

Fig. 8. WAXS patterns for the PC/MXD6 multilayer films thermally and watercrystallized, performed in the face and the cross section of the film.

films However, the obtained results displayed in Fig. 8 do not show any particular orientation of the crystals of MXD6 into the PC/MXD6 multilayer film.

In terms of barrier performances, comparing BIF-2 and BIF-3 put forward that the arrangement of the rigid MXD6 polymer chains in very thin layers appears as an efficient way to improve the barrier properties, and much more when MXD6 is crystallized. Also, by comparing the effect of the crystallization treatment to the multilayer structure on the barrier properties of MXD6, it appears that the geometrical restriction of MXD6 chains leads to better gas resistance than crystallized MXD6.

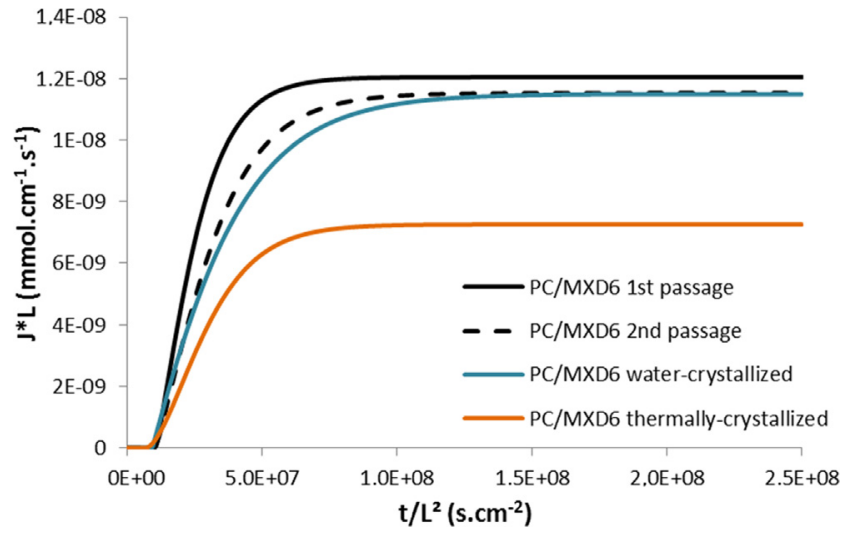

Fig. 9. Reduced water permeation curves for the initial and the crystallized PC/ MXD6 multilayer films.

From that, the question is about water, knowing that water molecules differ from gas molecules because interacting with polar groups of MXD6 and so not only structure-dependent.

Water permeation measurements were performed on the initial and crystallized PC/MXD6 multilayer films and the obtained curves are plotted in Fig. 9. In all cases, a typical water permeation curve was obtained. The water permeation kinetics through the water-crystallized multilayer film has reached a plateau at the same level as the noncrystallized PC/MXD6 multilayer film after two consecutive passages of water. This result would mean that, unlike the MXD6 monolayer film, the water crystallization treatment would have the same effect as two water permeations. However, there is a difference in terms of crystallinity degree. Indeed, after the first passage to water, the multilayer film presents a degree of crystallinity of $15 \%$ while the water-crystallized multilayer film exhibits $31 \%$ of crystallinity. It is therefore very surprising that the two films have a similar coefficient of permeability to water, around 1200 Barrer. It was expected that the water-crystallized multilayer film has a lower permeability coefficient, which should be close to the thermally-crystallized film one since it has a similar degree of crystallinity. Nevertheless, it can be noted that this lack of barrier effect of the water-crystallized multilayer film is associated with greater water diffusivity. Everything happens as if the transfer of water molecules was facilitated despite a greater presence of crystals. In fact, after water crystallization treatment, as previously mentioned for the MXD6 monolayer film, the presence of some microvoids or larger cavities in the MXD6 explain easily the increase of diffusivity and so the increase of water permeability.

However, with the PC/MXD6 multilayer film, unlike the MXD6 monolayer film, we get a significant difference between the two crystallization treatments (Table 5). Indeed, if the BIF of the thermallycrystallized PC/MXD6 film is relatively high (43\%) as the coefficient of water permeability is two times reduced, in the case of the watercrystallized PC/MXD6 film, the low value of the BIF indicates not so

Table 5

Liquid water permeation parameters for the PC/MXD6 multilayer film.

\begin{tabular}{llll}
\hline & $\mathrm{X}_{\mathrm{c}}(\%)$ & $\mathrm{P}($ Barrer $)$ & $\mathrm{D}\left(10^{-9} \mathrm{~cm}^{2} \cdot \mathrm{s}^{-1}\right)$ \\
\hline PC/MXD6 multilayer - 1st passage & 8 & $1225 \pm 250$ & $6 \pm 0.9$ \\
PC/MXD6 multilayer - 2nd passage & 15 & $1210 \pm 110$ & $5.5 \pm 0.8$ \\
$\begin{array}{l}\text { PC/MXD6 multilayer - water } \\
\quad \text { crystallized }\end{array}$ & 31 & $1162 \pm 100$ & $6.7 \pm 1$ \\
BIF & - & $5 \%$ & - \\
PC/MXD6 multilayer - thermally- & 35 & $697 \pm 16$ & $4.3 \pm 0.5$ \\
$\quad$ crystallized & & $43 \%$ & -
\end{tabular}

* Calculated from the PC/MXD6 multilayer film presenting a degree of crystallinity of $8 \%$. 
much effect of the presence of crystals, the microvoids having an opposite effect which favors water diffusivity. This trend is in agreement with the gas permeation results. For the thermally-crystallized PC/ MXD6 film, the decrease of the water diffusion coefficient is characteristic of a longer mean diffusion pathway that is expected since the increase in the crystallinity level (from $8 \%$ to $35 \%$ after annealing) made more tortuous the passage of the diffusing species. The barrier effect improvement is very encouraging because we must keep in mind that the multilayer film contains only $20 \mathrm{wt} \%$ of MXD6 and that the thermal treatment has only an effect on the semi-crystalline MXD6 polymer without acting on the amorphous polycarbonate composing the multilayer film.

\section{Conclusion}

In this work, we report the crystallization of a PC/MXD6 film composed of a thousand micrometric layers, in order to further improve its barrier performances. Two crystallization treatments have been applied on this multilayer system, the first one by heating and the second one by immersing the sample in water because of the capacity of MXD6 to crystallize in contact with it. If both treatments led to the same degree of crystallization around $30 \%$, the improvement in the gas and water barrier properties of films was found different. For the films crystallized by water, the improvement of barrier properties was lower despite the similar increase in the degree of crystallinity. This result was due to the creation of microvoids in MXD6 induced by the water immersion while in the case of the thermally crystallized MXD6, the initial structure of the film was maintained, that means without formation of microvoids, and that allowed a higher improvement in barrier properties. It was then interesting to constrain crystallized MXD6 film in thin layers to see at which point the barrier effect can be enhanced. Thus, the use of the forced assembly process for preparing PC/MXD6 multilayer film was clearly evidenced, PC being used as a confiner polymer. PC/MXD6 multilayers composed of 1025 layers alternating PC layers and MXD6 layers were successfully realized. The geometrical constraint effect induced by PC associated with the increase in crystallinity of the MXD6 layers allowed a significant improvement of the gas and water barrier properties. This procedure appears as a promising way to develop new materials with enhanced properties and which can be implemented at the industrial scale.

\section{Supporting information}

Comparison of the DSC curves for the initial MXD6 film and the MXD6 films thermally and water crystallized.

\section{Acknowledgment}

The authors thank the GRR Crunch (supported by Upper Normandy region, France) for the financial support of the PhD fellowship of $\mathrm{T}$. Messin.

\section{Appendix A. Supplementary material}

Supplementary data to this article can be found online at https:// doi.org/10.1016/j.eurpolymj.2018.12.021.

\section{References}

[1] Y. Michiels, P. Van Puyvelde, B. Sels, Barriers and chemistry in a bottle: mechanisms in today's oxygen barriers for tomorrow's materials, Appl. Sci. 7 (2017) 665-694.

[2] C. Ge, J. Popham, A review and evaluation of prediction models of gas permeation for a blended flexible packaging film, Packag. Technol. Sci. 29 (2016) 247-262.

[3] J. Feng, Z. Li, A. Olah, E. Baer, High oxygen barrier multilayer EVOH/LDPE film/ foam, J. Appl. Polym. Sci. 135 (2018) 46425 (1-9).

[4] H. Wang, J.K. Keum, A. Hiltner, E. Baer, B. Freeman, A. Rozanski, A. Galeski,
Confined crystallization of polyethylene oxide in nanolayers assemblies, Science 323 (2009) 757-760.

[5] M. Gupta, Y. Lin, T. Deans, E. Baer, A. Hiltner, D.A. Schiraldi, Structure and Gas barrier properties of poly(propylene-graft-maleic anhydride)/phosphate glass composites prepared by microlayer coextrusion, Macromolecules 43 (2010) $4230-4239$.

[6] G. Zhang, P.C. Lee, S. Jenkins, J. Dooley, E. Baer, The effect of confined spherulite morphology of high-density polyethylene and polypropylene on their gas barrier properties in multilayered film systems, Polymer 55 (2014) 4521-4530.

[7] Y. Lin, A. Hiltner, E. Baer, A new method for achieving nanoscale reinforcement of biaxially oriented polypropylene film, Polymer 51 (2010) 4218-4224.

[8] M. Boufarguine, A. Guinault, G. Miquelard-Garnier, C. Sollogoub, PLA/PHBV films with improved mechanical and gas barrier properties, Macromol. Mater. Eng. 298 (2013) 1065-1073.

[9] D.S. Langhe, A. Hiltner, E. Baer, Melt crystallization of syndiotactic polypropylene in nanolayers confinement impacting structure, Polymer 52 (2011) 5879-5889.

[10] H. Wang, J.K. Keum, A. Hiltner, E. Baer, Confined crystallization of PEO in nanolayered films impacting structure and oxygen permeability, Macromolecules 42 (2009) 7055-7066.

[11] H.P. Wang, J.K. Keum, A. Hiltner, E. Baer, Crystallization kinetics of poly(ethylene oxide) in confined nanolayers, Macromolecules 43 (2010) 3359-3364.

[12] M. Mackey, L. Flandin, A. Hiltner, E. Baer, Confined crystallization of PVDF and a PVDF-TFE copolymer in nanolayered films, J. Polym. Sci. Part B: Polym. Phys. 49 (2011) 1750-1761.

[13] T. Messin, N. Follain, A. Guinault, G. Miquelard-Garnier, C. Sollogoub, N. Delpouve, V. Gaucher, S. Marais, Confinement effect in PC/MXD6 multilayer films: impact of the microlayered structure on water and gas barrier properties, J. Memb. Sci. 525 (2017) 135-145.

[14] M. Fereydoon, S.H. Tabatabaei, A. Ajji, Rheological, crystal structure, barrier, and mechanical properties of PA6 and MXD6 nanocomposite films, Polym. Eng. Sci. 54 (2014) 2617-2631.

[15] Y.S. Hu, S. Mehta, D.A. Schiraldi, A. Hiltner, E. Baer, Effect of water sorption on oxygen-barrier properties of aromatic polyamides, J. Polym. Sci. Part B Polym. Phys. 43 (2005) 1365-1381.

[16] B. Ben Doudou, E. Dargent, S. Marais, J. Grenet, Y. Hirata, Barrier properties and microstructure modifications induced by liquid water for a semiaromatic polyamide, J. Polym. Sci. Part B Polym. Phys. 43 (2005) 2604-2616.

[17] C.L. Buquet, B. Ben Doudou, C. Chappey, E. Dargent, S. Marais, Permeation properties of poly(m-xylene adipamide) membranes, J. Phys. Chem. B 113 (2009) 3445-3452.

[18] T. Ohta, Y. Fujiwara, Y. Toshimori, K. Monobe, Single crystals of poly(m-xylylene adipamide), Polymer 33 (1992) 1620-1622.

[19] C. Rogers, J.A. Meyer, V. Stannet, M. Szwarc, Studies in the gas and vapor permeability of plastic films and coated papers, Tappi 39 (1956) 737-747.

[20] Y. Hirata, S. Marais, Q.T. Nguyen, C. Cabot, J.-P. Sauvage, Relationship between the gas and liquid water permeabilities and membranes structure in homogeneous and pseudo-bilayer membranes based on partially hydrolyzed poly(ethylene-co-vinyl acetate), J. Memb. Sci. 256 (2005) 7-17.

[21] S. Marais, Y. Hirata, D. Langevin, C. Chappey, T.Q. Nguyen, M. Metayer, Permeation and sorption of water and gases through EVA copolymers films, Mater. Res. Innov. 6 (2002) 79-88.

[22] N. Follain, J.-M. Valleton, L. Lebrun, B. Alexandre, P. Schaetzel, M. Metayer, S. Marais, Simulation of kinetic curves in mass transfer phenomena for a concentration-dependent diffusion coefficient in polymer membranes, J. Memb. Sci. 349 (2010) 195-207.

[23] Y.S. Hu, V. Prattipati, S. Mehta, D.A. Schiraldi, A. Hiltner, E. Baer, Improving gas barrier of PET by blending with aromatic polyamides, Polymer 48 (2005) 2685-2698.

[24] C. Thellen, S. Schirmer, J.A. Ratto, B. Finnigan, D. Schmidt, Co-extrusion of multilayer poly(mxylylene adipimide) nanocomposite films for high oxygen barrier packaging applications, J. Memb. Sci. 340 (2009) 45-51.

[25] Y. Wang, S.A. Jabarin, Novel preparation method for enhancing nanoparticule dispersion and barrier porperties of poly(ethylene terephthalate) and poly(m-xylylene adipamide), J. Appl. Polym. Sci. 129 (2013) 1455-1465.

[26] A. Pawlak, A. Galeski, A. Rozanski, Cavitation during deformation of semicrystalline polymers, Prog. Polym. Sci. 39 (2014) 921-958.

[27] J.H. Petropoulos, Mechanisms and theories for sorption and diffusion of gases in polymers, Chapter 2 of Polymeric gas separation membranes, 1994, pp. 17-81.

[28] D.W. Van Krevelen, Properties of Polymers, 3rd ed., Elsevier, Amsterdam/Oxford, 1990.

[29] I. Puente Orench, N. Stribeck, F. Ania, E. Baer, A. Hiltner, F.J. Balta Calleja, SAXS study on the crystallization of PET under physical confinement in PET/PC multulayered films, Polymer 50 (2009) 2680-2687.

[30] A. Flores, C. Arribas, F. Fauth, D. Khariwala, A. Hiltner, E. Baer, F.J. Balta-Calleja, F. Ania, Finite size effects in multilayered polymer systems: development of PET lamellae under physical confinement, Polymer 51 (2010) 4530-4539.

[31] V. Prattipati, Y.S. Hu, S. Bandi, D.A. Schiraldi, A. Hiltner, E. Baer, S. Mehta, Effect of compatibilization on the oxygen-barrier properties of poly(ethylene terephthalate)/ poly(m-xylylene adipamide) blends, J. Appl. Polym. Sci. 97 (2005) 1361-1370.

[32] T. Messin, N. Follain, A. Guinault, C. Sollogoub, V. Gaucher, N. Delpouve, S. Marais, Structure and barrier properties of multi-nanolayered biodegradable PLA/PBSA films: confinement effect via forced assembly coextrusion, ACS Appl. Mater. Interfaces 9 (2017) 29101-29112.

[33] M. Ponting, Y. Lin, J.K. Keum, A. Hiltner, E. Baer, Effect of substrate on the isothermal crystallization kinetics of confined poly (e-caprolactone) nanolayers, Macromolecules 43 (2010) 8619-8627. 